\title{
Hypertension in the Parsi community of Bombay: a study on prevalence, awareness and compliance to treatment Nadir E Bharucha and Thomas Kuruvilla*
}

\author{
Address: Department of Neuroepidemiology, Medical Research Center, Bombay Hospital, Mumbai-400020 India \\ Email: Nadir E Bharucha - nbharucha@vsnl.com; Thomas Kuruvilla* - olasa@vsnl.com \\ * Corresponding author
}

Published: 6 January 2003

BMC Public Health 2003, 3:1
Received: 25 October 2002

Accepted: 6 January 2003

This article is available from: http://www.biomedcentral.com/I47/-2458/3/I

(C) 2003 Bharucha and Kuruvilla; licensee BioMed Central Ltd. This is an Open Access article: verbatim copying and redistribution of this article are permitted in all media for any purpose, provided this notice is preserved along with the article's original URL.

\begin{abstract}
Background: Uncontrolled hypertension (HT) is an established risk factor for the development of vascular diseases. Prevalence varies in different communities and no such study has been conducted in the Parsi community living in Bombay, India. The objectives of this study were to determine the prevalence, awareness, compliance to medication and control of HT in this community.
\end{abstract}

Method: We used a $\mathrm{I}$ in 4 random selection of subjects who were $\geq 20$ years of age. A questionnaire was administered and the blood pressure (BP) was measured by a doctor. HT was defined as diastolic blood pressure $(D B P) \geq 90 \mathrm{~mm} \mathrm{Hg} \pm$ systolic pressure (SBP) $\geq 140 \mathrm{~mm} \mathrm{Hg}$. Isolated systolic hypertension (ISH) was defined as SBP $\geq 160 \mathrm{~mm} \mathrm{Hg}$ with DBP $<90 \mathrm{~mm} \mathrm{Hg}$. Subsequently, we reanalysed the data using current definition of ISH as SBP $\geq 140 \mathrm{~mm} \mathrm{Hg}$ with DBP $<90 \mathrm{~mm} \mathrm{Hg}$.

Results: 2879 subjects $\geq 20$ years of age were randomly selected of which 2415 (84\%) participated in the study. The overall prevalence of $\mathrm{HT}$ in the community was $36.4 \%$, of whom $48.5 \%$ were unaware of their hypertensive status. Of those aware of having HT, 36.4\% were non-compliant with their anti-hypertensive drugs and only $13.6 \%$ had optimally controlled HT. Prevalence of ISH using the present criteria was $19.5 \%$ and $73 \%$ of hypertensives $\geq 60$ years had ISH.

Conclusion: This study shows that prevalence of HT in the Parsi community is high and nearly half are unaware of their hypertensive status. ISH is the dominant form of HT in the elderly. Compliance to treatment is poor and optimal BP control is achieved in only a small minority. The study highlights the need for regular screening coupled with educational programs to detect and optimally treat HT in the community.

\section{Background}

The Parsis, followers of the Bronze Age Prophet Zarathushtra, migrated to India from Iran between the seventh and tenth centuries AD [1]. This small community is relatively affluent, having ready access to medical care. It has an 'ageing' demographic profile with a large number of middle aged and elderly. In this respect it is more similar to the demographic profile seen in developed countries, unlike the profile of the general Indian population which is predominantly young (Table 1). The community does not accept religious conversions, and allows very little intermarriage with other religions [2]. As a conse- 
Table I: Percentage distribution of population by age groups

\begin{tabular}{|c|c|c|c|}
\hline Age group (in years) & India (198I census) & USA (1980) & Parsis (1985 survey) \\
\hline $0-9$ & 26.7 & 14.6 & 7.4 \\
\hline $10-19$ & 22.5 & 17.4 & 10.4 \\
\hline $20-29$ & 16.2 & 18.0 & 11.6 \\
\hline $30-39$ & 12.3 & 14.0 & 13.0 \\
\hline $40-49$ & 9.5 & 10.1 & 13.2 \\
\hline $50-59$ & 6.3 & 10.3 & 15.9 \\
\hline $60-64$ & 2.7 & 4.5 & 8.1 \\
\hline $65+$ & 3.8 & 11.3 & 20.5 \\
\hline Total & $100 \%$ & $100 \%$ & $100 \%$ \\
\hline
\end{tabular}

quence, its population has been declining at a rate of about $10 \%$ every decade and UNESCO has initiated a project (Project 302 IND 70) to preserve the community's unique culture and heritage. The findings of the present study will be used in the 'medical module' of the project.

In India, as in most other countries, hypertension (HT) is a major public health problem, with the prevalence in urban areas estimated to be about $27-32 \%$. Moreover, most studies have shown that compliance to medication is poor and optimal blood pressure (BP) control is achieved in less than $10 \%$ of hypertensives.

In 1985, a prevalence study of neurological diseases among the Parsis living in the colonies of Bombay was conducted. It was found that the prevalence of stroke in this population was $842.3 / 100,000$ with HT being the most important risk factor [3,4]. As a follow up of this observation, the present study was conducted to assess the prevalence of HT in the community, prior awareness, compliance to anti-hypertensive medication and extent of BP control.

\section{Method}

Approximately $71 \%$ of the 91,000 Parsis in India live in the city of Bombay [2]. About one-third of the Parsis in Bombay reside in large groups of houses known as colonies. These colonies were built in earlier years by wealthy Parsis for the less affluent members of the group. Most of these people have lived there for years, even after their social circumstances improved.

In the 1985 survey, on prevalence day, there were 14,010 people living in 4,537 households. For the present study, we arranged men and women $\geq 20$ years in ascending order by age and, using a random number generator, we chose a one in four sample for each colony for men and women separately (implicit stratification). High school graduates, a social worker and a doctor administered a questionnaire to each person after taking written in- formed consent. The questionnaire was designed to elicit information on family history of HT, prior BP measurement, awareness of HT (from family physicians or other heath care providers) and treatment taken. In addition, data regarding height and weight of the subject and history of tobacco and alcohol consumption were recorded.

The doctor took the BP using a Hawksley random zero Syphgmomanometer. This instrument reduces observer bias and digit preference by 'muddling' the zero levels and has been widely used in epidemiological surveys [5]. Two BP readings were taken during the same visit. The first reading was taken during the initial part of the interview and the second towards the end with the subject at rest. Importance was given to the second reading in order to try to eliminate factors like anxiety and stress that are known to increase the BP physiologically.

HT was defined as diastolic BP (DBP) $\geq 90 \mathrm{~mm} \mathrm{Hg} \pm \mathrm{a}$ systolic BP (SBP) $\geq 140 \mathrm{~mm} \mathrm{Hg}$. Subjects having normal $\mathrm{BP}$ on examination but who were taking anti-hypertensive medicines regularly were included in the hypertensive category. Isolated systolic hypertension (ISH) was defined as $\mathrm{SBP} \geq 160 \mathrm{~mm} \mathrm{Hg}$ with DBP $<90 \mathrm{~mm} \mathrm{Hg}$. This was the criterion for ISH used in the SHEP study [6] and was the criterion being used when the present study was initiated. Current recommendations define ISH as SBP $\geq 140 \mathrm{~mm}$ Hg with DBP < 90 mm Hg [7]. Subsequently, we re-analysed our findings using the new criteria for ISH to compare our results with other recent studies.

\section{Results}

Of the 2879 persons selected, 2415 (84\%) participated in the study (Table 2). The percentage of men and women were $45.5 \%$ (1099) and 54.5\% (1316) respectively. Most of the subjects had easy access to a doctor and $90.2 \%$ reported having had their BP checked in the recent past.

The overall prevalence of HT (including ISH) was calculated by adding those with optimally controlled BP (due to 
Table 2: Profile of those who participated in the study

\begin{tabular}{llll}
\hline Age group in years & Men & Women & Men + Women \\
\hline $20-29$ & 152 & 170 & 322 \\
$30-39$ & 169 & 201 & 370 \\
$40-49$ & 188 & 203 & 391 \\
$50-59$ & 214 & 289 & 503 \\
$60-69$ & 213 & 239 & 452 \\
$70+$ & 163 & 214 & 377 \\
Total & 1099 & 1316 & $\mathbf{2 4 1 5}$ \\
\hline
\end{tabular}

Table 3: Prevalence of hypertension in men

\begin{tabular}{|c|c|c|c|c|}
\hline Age group (years) & $\begin{array}{l}\text { 'Diastolic' HT (including } \\
\text { optimally controlled HT }\end{array}$ & $\begin{array}{l}\text { Borderline ISH } \\
\text { (SBP: I } 40-159 \mathrm{mmHg} \text { with } \\
\text { DBP }<90 \mathrm{~mm} \mathrm{Hg} \text { ) }\end{array}$ & $\begin{array}{l}\text { ISH }(S B P \geq 160 \mathrm{~mm} \mathrm{Hg} \\
\text { DBP }<90 \mathrm{~mm} \mathrm{Hg})\end{array}$ & Overall prevalence \\
\hline 20-29 & $11.2 \%(17)$ & $2.0 \%(3)$ & - & $13.2 \%(20 / 152)$ \\
\hline $30-39$ & $16.0 \%(27)$ & $1.2 \%(2)$ & - & $17.2 \%(29 / 169)$ \\
\hline $40-49$ & $23.4 \%(44)$ & $3.2 \%(6)$ & $1.6 \%(3)$ & $28.2 \%(53 / 188)$ \\
\hline $50-59$ & $24.3 \%(52)$ & $10.8 \%(23)$ & $1.9 \%(4)$ & $36.9 \%(79 / 214)$ \\
\hline $60-69$ & $16.0 \%(34)$ & $22.6 \%(48)$ & $5.2 \%(\mathrm{II})$ & $43.7 \%(93 / 213)$ \\
\hline $70+$ & $12.9 \%(21)$ & $26.4 \%(43)$ & $13.5 \%(22)$ & $52.8 \%(86 / 163)$ \\
\hline Total & & & & $32.8 \%(360 / 1099)$ \\
\hline
\end{tabular}

HT: hypertension; 'diastolic' HT: diastolic BP $\geq 90 \mathrm{~mm} \mathrm{Hg}$ with normal or elevated systolic BP; ISH: isolated systolic hypertension; SBP: systolic blood pressure; DBP: diastolic blood pressure

regular anti-hypertensive medication) with those having high $\mathrm{BP}$ on examination. Using the current definition, prevalence of HT (including ISH) was $32.8 \%$ (360 of 1099 ) in men and $39.4 \%$ (519 of 1316) in women with a mean prevalence of $36.4 \%$ in those $\geq 20$ years of age. Prevalence in the different age groups is shown in Table 3 and 4.

While estimating prevalence of ISH, we only considered those having ISH on examination. This would underestimate to some extent the prevalence of ISH, as those on regular anti-hypertensive medication and with a $\mathrm{BP}$ of $<$ 140/90 mm Hg were considered to have controlled 'diastolic HT'. Prevalence of ISH using the SHEP criteria was 6.9\% (men: $3.6 \%$ women: $9.7 \%$ ). Prevalence using the JNC VI criteria was $15 \%$ in men and $23.3 \%$ in women with mean prevalence being $19.5 \%$. Among those suffering from HT, the proportion having ISH progressively increases with age. In those $\geq 60$ years, ISH (using the SHEP criteria) comprised $53.2 \%$ of hypertensives (men $37.5 \%$; women $60.8 \%$ ) and using the new criteria comprised $73 \%$ of those with HT (men 69.3\%; women 75.3\%). Corresponding figures in those $\geq 70$ years are $65.5 \%$ - men $51.2 \%$, women $71.7 \%$ - (using the SHEP criteria) and
$79.8 \%$ - men $75.6 \%$ and women $82.1 \%$ - (using the new criteria).

While calculating awareness, we considered ISH as SBP $\geq$ $160 \mathrm{~mm} \mathrm{Hg}$ with DBP $<90 \mathrm{~mm} \mathrm{Hg}$ as this was the criteria used for defining ISH at the time of the study. Among men, $47 \%$ were aware of their hypertensive status while among women, $56 \%$ were aware. Compliance to medication was regular in $63.3 \%$ of men and in $64 \%$ of women.

A subject was considered to have optimally controlled HT if he or she had a DBP $<90 \mathrm{~mm}$ Hg with SBP $<160 \mathrm{~mm}$ $\mathrm{Hg}$ while on regular anti-hypertensive medication. Using this criteria, optimal BP control was achieved in only $13.6 \%$ of those who were aware of having HT (men: $11.6 \%$; women: $15 \%)$.

\section{Discussion}

There is a paucity of large, well designed, population based studies on HT in India [8]. Earlier studies on the prevalence of HT in India considered HT to be $\geq 160 / 95$ $\mathrm{mm} \mathrm{Hg}$ while the later studies used the current definition of $\mathrm{HT}$ as $\geq 140 / 90 \mathrm{~mm} \mathrm{Hg}$. To maintain uniformity, we compared our findings with those of some recent Indian studies that used the newly recommended criteria. The 
Table 4: Prevalence of hypertension in women

\begin{tabular}{lllll}
\hline Age group (years) & $\begin{array}{l}\text { 'Diastolic' HT (including } \\
\text { optimally controlled HT }\end{array}$ & $\begin{array}{l}\text { Borderline ISH } \\
\text { (SBP: I } 140-159 \mathrm{mmHg} \text { with } \\
\text { DBP }<90 \mathrm{~mm} \mathrm{Hg})\end{array}$ & $\begin{array}{l}\text { ISH }(\mathrm{SBP} \geq \mathrm{I} \mathbf{6 0} \mathrm{mm} \mathrm{Hg} \\
\mathrm{DBP}<90 \mathrm{~mm} \mathrm{Hg})\end{array}$ & Overall prevalence \\
\hline $20-29$ & $7.1 \%(12)$ & $1.8 \%(3)$ & $0.6 \%(1)$ & $9.4 \%(16 / 170)$ \\
$30-39$ & $11.0 \%(22)$ & $1.5 \%(3)$ & - & $12.4 \%(25 / 201)$ \\
$40-49$ & $18.2 \%(37)$ & $6.4 \%(13)$ & $2.0 \%(4)$ & $26.6 \%(54 / 203)$ \\
$50-59$ & $24.2 \%(70)$ & $18.3 \%(53)$ & $4.5 \%(13)$ & $47.1 \%(136 / 289)$ \\
$60-69$ & $18.0 \%(43)$ & $21.0 \%(50)$ & $16.3 \%(39)$ & $55.2 \%(132 / 239)$ \\
$70+$ & $13.1 \%(28)$ & $26.6 \%(57)$ & $33.2 \%(71)$ & $72.9 \%(156 / 214)$ \\
Total & & & $39.4 \%(519 / 1316)$
\end{tabular}

HT: hypertension; 'diastolic' HT: diastolic BP $\geq 90 \mathrm{~mm} \mathrm{Hg}$ with normal or elevated systolic BP; ISH: isolated systolic hypertension; SBP: systolic blood pressure; DBP: diastolic blood pressure

findings of the third National Health and Nutrition Examination Survey (NHANES III) of the American population [9] will be used to compare our findings in the Parsi community with that of a developed country.

In rural India, some studies have shown a low prevalence of about 3-4\% [8]. However, more recent studies, using current criteria for HT, shows a prevalence of $21 \%$ (24\% in men and $17 \%$ in women) in rural India and 32\% (30\% in men and $33 \%$ in women) in urban India $[10,11]$. In the Parsi study, prevalence of HT in the adult population was $35.8 \%$ (31.9\% in men and 39\% in women). In the American population, prevalence of HT was $27 \%$ in those $\geq 25$ years [9]. While assessing prevalence, one needs to take into account the demographic profile of the population under study because prevalence of HT increases with age. As seen in Table 1, the general Indian population (1981 census) is young with $77 \%$ being less than 40 years of age. In the American population (1980), 64.4\% were less than 40 years while in the Parsi community (1985 survey) only $42.4 \%$ were less than 40 years. If we were to age standardise the prevalence of HT with that of the 1981 Indian population, the crude prevalence rate of HT would be $24.7 \%$ in men and $24.6 \%$ in women. This is significantly less than the figures of $30 \%$ and $33 \%$ for men and women respectively found in urban north India [11]. On the other hand, the age standardised prevalence for the American population (of 1980 ) would be $29.4 \%$, which is similar to the actual prevalence of $27 \%$ observed in the NHANES III survey. These findings suggest that, unlike common perception, HT is a greater public health problem in developing countries than in developed countries

Kalavathy and colleagues[12], found that $51.8 \%$ of the elderly in Kerala, South India, had HT. The Hypertension Study Group[13], in their multi-centre study, found that the overall prevalence of HT in the elderly was $65 \%$. Our study also showed a progressively increasing prevalence with age, with $56.3 \%$ of those $\geq 60$ years and $64.2 \%$ of those $\geq 70$ years having HT.

Using the SHEP criteria, prevalence of ISH was $6.9 \%$ in our study compared to the prevalence of about $10 \%$ in the SHEP study. Using the current criterion for defining ISH, prevalence in our study was $19.5 \%$ (15\% in men and $23.3 \%$ in women). In contrast, studies have shown that the prevalence of ISH in rural India is only about $3.4 \%$ while in urban areas it is about $6.2 \%$ (6\% in men and $6.3 \%$ in women) $[10,11]$. The age standardized prevalence for the adult Indian population would be $7.7 \%$ and $11.6 \%$ in men and women respectively which is still less than that observed in the Parsi community. The Parsi study also shows that prevalence of HT, especially ISH, is significantly more in women than in men. The reason for this difference is not clear.

Our study shows that with increasing age progressively more subjects with HT have ISH rather than 'diastolic' HT. A recent Indian study [15] showed that the prevalence of ISH in subjects attending a HT clinic was $56.6 \%$ in those $>60$ years of age. In the Parsi study, in those $\geq 60$ years, $53.2 \%$ and $73 \%$ of hypertensives had ISH using the SHEP and present criteria respectively. This observation is important because many physicians continue to disregard the importance of treating mild increases in SBP. In the American survey, it was found that $>75 \%$ of those unaware and $>60 \%$ of those aware of their hypertensive status but with uncontrolled HT had only mildly elevated systolic HT[14].

In the Parsi study, $53 \%$ of men and $44 \%$ of women were unaware of their hypertensive status. This large figure is surprising considering that $90.2 \%$ of those interviewed had had their BP measured in the recent past. Lack of awareness is high in most Indian communities. It is especially high in the rural population of Western India where 
92.5\% were unaware[10]. The survey of the American population also revealed a high percentage (31\%) of subjects being unaware of their hypertensive status $[9,14]$ but this is significantly less than that in the Parsi community.

In the Hypertension Study Group survey [13], compliance to medication was $40 \%$ among the elderly. In urban Delhi, compliance was only $30 \%$ in those aware of having hypertension [16]. Compared to these figures, compliance to medication was better in the Parsi community (64\%) but was still significantly less than the $83 \%$ compliance reported in the American population [14].

Most Indian studies have shown that optimal BP control was achieved in only a small proportion of those who were aware of having HT. Optimal control was present in only $10 \%$ in the Hypertension Study Group [13] while in urban Delhi [16] it was only 9\%. In our study, it was only marginally higher at $13.6 \%$. The NHANES III survey also found that optimal BP control was achieved only in $23 \%$ of the American population [14].

An important limitation of our study is that we did not use the JNC VI criteria for defining ISH in our initial analysis of data. Although we subsequently re-analyzed the data using the new criteria, this was applicable only for estimating prevalence. Awareness, compliance and optimal $\mathrm{BP}$ control had to be estimated using the old criteria as these were in use when the study was initiated. Secondly, as mentioned above, there would have been some underestimation of the prevalence of ISH as patients on regular medication and controlled HT were classified as having 'diastolic HT'. Other limitations include study of a single community and BP measurement on a single day which could over-estimate prevalence due to 'white-coat' effect among other factors.

\section{Conclusion}

This study shows that more than a third of the adult members of the Parsi community suffer from HT and nearly half of those having HT are unaware of their illness. Compliance to medication is poor and only a small minority have optimally controlled blood pressures. ISH is present in about three-fourths of elderly hypertensives and many of these subjects have only mild increases in systolic pressure. Finally, our study shows that even in relatively affluent communities, with ready access to medical care, there is an urgent need for regular screening for HT coupled with educational programs to emphasize the benefits of optimal BP control.

\section{Competing interests}

None declared.

\section{Authors contribution}

NEB was instrumental in initiating the study, formulating the study design, and carrying out the study.

TK was instrumental in completing the study, analyzing data and preparing the manuscript for publication.

Both the authors have read and approved the final manuscript.

\section{Acknowledgements}

We are deeply indebted to Dr. Adil Bharucha for performing the blood pressure measurements, and to Dr. Dallas W. Anderson for providing technical advice. We acknowledge the commitment of the social workers and volunteers who did the door-to-door survey. Also, our sincere gratitude to the Birla Smarak Kosh for financing this project and the staff of the Dept. of Neuroepidemiology, Bombay Hospital, for help in data analysis.

\section{References}

I. Mistree KP Zoroastrianism: An ethnic perspective. Bombay: K.R. Cama Oriental Institute 1982,

2. Karkal M Marriage behavior and demographic transitions among Parsis. In: Dynamics of population and family welfare, Bombay (Edited by: Srinivasan K, Mukherjee S) Himalaya Publishing House 1983, 397-410

3. Bharucha NE, Bharucha EP, Dastur HD and Schoenberg BS Pilot survey of the prevalence of neurological disorders in the Parsi community of Bombay. Am J Prev Med 1987, 3(5):293-9

4. Bharucha NE, Bharucha EP, Bharucha AE, Bhise AV and Schoenberg BS Prevalence of Stroke in the Parsi Community of Bombay. Stroke 1988, 19(1):60-62

5. Rose GA, Holland WW and Crowly EA A Sphygmomanometer for Epidemiologists. Lancet 1964, I:296-300

6. SHEP Cooperative Research Group Prevention of Stroke by Antihypertensive Drug Treatment in Older Persons with Isolated Systolic Hypertension in the Elderly Program (SHEP). JAMA 199I, 265:3255-3264

7. The Sixth Report of the Joint National Committee on Prevention, Detection, Evaluation and Treatment of High Blood Pressure. Arch Intern Med 1997, 1557:2413-2446

8. Epidemiology of hypertension. In: Indian Guidelines in Management of Hypertension (Edited by: Shah SN) Hypertension India (Official publication of the Hypertension Society of India) 200I, I 1(2):5-6

9. National Center for Health Statistics Plan and operation of the third National Health and Nutrition Examination Survey, 1988-94. Vital and health statistics. Series I. No. 32. Washington, D.C.: Government Printing Office July 1994

10. Gupta $R$ and Sharma AK Prevalence of hypertension and subtypes in an Indian rural population: clinical and electrocardiographic correlates. J Hum Hypertens 1994, 8(I I):823-9

II. Gupta R, Guptha S, Gupta VP and Prakash H Prevalence and determinants of hypertension in the urban population of Jaipur in western India. J Hypertens 1995, I3(10): I 193-200

12. Kalavathy MC, Thankappan KR, Sarma PS and Vasan RS Prevalence, awareness, treatment and control of hypertension in an elderly community-based sample in Kerala, India. Natl Med J India 2000, I3(I):9-15

13. Hypertension Study Group Prevalence, awareness, treatment and control of hypertension among the elderly in Bangladesh and India: a multicentre study. Bull World Health Organ 200I, 79(6):490-500

14. Hyman DJ and Pavlik VN Characteristics of patients with uncontrolled hypertension in the United States. NEJM 200I, 345:479-486

15. Kulkarni V, Bhagwat N, Hakim A, Kamath S and Soneji SL Hypertension in the Elderly. J Assoc Phy India (JAPI) 200I, 49:873-876

16. Chadha SL, Radhakrishnan S, Ramachandran K, Kaul U and Gopinath $\mathrm{N}$ Prevalence, awareness \& treatment status of hypertension in urban population of Delhi. Indian J Med Res 1990, 92:233-40 


\section{Pre-publication history}

The pre-publication history for this paper can be accessed here:

http://www.biomedcentral.com/1471-2458/3/1/prepub

Publish with Bio Med Central and every scientist can read your work free of charge

"BioMed Central will be the most significant development for disseminating the results of biomedical research in our lifetime. " Sir Paul Nurse, Cancer Research UK

Your research papers will be:

- available free of charge to the entire biomedical community

- peer reviewed and published immediately upon acceptance

- cited in PubMed and archived on PubMed Central

- yours - you keep the copyright 